\title{
0985. Open lung ventilation improves conditions for right ventricle performance by decreasing pulmonary vascular wave reflections in an experimental model of ARDS
}

\author{
A Santos ${ }^{1,2,3^{*}}$, E Gomez Peñalver ${ }^{2}$, JB Borges ${ }^{1}$, J Retamal ${ }^{1}$, Ml Monge García ${ }^{4}$, G Tusman ${ }^{5}$, A Larsson ${ }^{1,6}$, \\ G Hedenstierna' ${ }^{1}$ F Suarez-Sipmann ${ }^{1,6}$
}

From ESICM LIVES 2014

Barcelona, Spain. 27 September - 1 October 2014

\section{Introduction}

Impaired right ventricle (RV) function is associated with worse outcome in ARDS. Pulmonary artery pressure waveform analysis provides information about phenomena that affect RV performance. In particular, pulmonary vascular wave reflection (WR) is directly related with RV stress. We hypothesised that open lung ventilation (OLV), compared with conventional ARDS-net ventilation (CV), would improve conditions for RV performance in an ARDS model. This hypothesis was tested by measuring pulmonary vascular wave reflection (WR).

\section{Objectives}

To evaluate the effect of two mechanical ventilation (MV) strategies on WR in an experimental model of ARDS.

\section{Methods}

8 anesthetized and muscle relaxed pigs were submitted to a two-hit lung injury model combining repeated lung lavages with injurious MV. After lung injury was induced, animals were randomized (4 pigs in each group) to one of two strategies of MV: OLV, PEEP $2 \mathrm{cmH} 2 \mathrm{O}$ above the PEEP corresponding with the maximal dynamic compliance in a decreasing PEEP trial after a recruitment manoeuvre; or CV, PEEP adjusted according to the ARDSnetwork table. In both groups tidal volume was $6 \mathrm{ml} /$ $\mathrm{kg}$, respiratory rate to maintain $\mathrm{PaCO} 2$ between 55-65 $\mathrm{mmHg}$ and $\mathrm{FIO} 2$ to maintain $\mathrm{PaO} 255-80 \mathrm{mmHg}$.

'Uppsala University, Hedenstierna Laboratory, Surgical Sciences Department, Uppsala, Sweden

Full list of author information is available at the end of the article
Pulmonary artery (PA) flow and pressure waveforms $(1000 \mathrm{~Hz}$ sampling rate) were acquired by a high-fidelity microtip manometer and an instantaneous transonic pulmonary flow probe placed in the main PA by a small lateral thoracotomy. These signals were used to separate the forward and backward components of the pressure waveform $^{1}$ and quantify WR. The following indexes of WR were calculated: Backward wave amplitude (APbw); Reflection index (RI) which is the ratio between the backward wave amplitude and the sum of backward and forward wave amplitude. Evaluation was done before (BL) and after lung injury (ARDS) and after 4 hours of management in the respective MV strategy.

\section{Results}

We did not find any significant changes by induction of ARDS but both APbw $(5.28 \pm 1.35$ vs $10.85 \pm 2.16 \mathrm{mmHg}$, $\mathrm{p}=0.021)$ and RI $(0.28 \pm 0.04$ vs $0.39 \pm 0.04, \mathrm{p}=0.021)$ were lower in OLV comparing with CV.

\section{Conclusions}

In this experimental ARDS-model OLV decreased WR in the pulmonary vascular system comparing with $\mathrm{CV}$, indicated that OLV could reduce the stress on the RV and improve conditions for RV performance.

\section{Grant acknowledgment}

This study is part of a project awarded by the ECCRN of the ESICM (Basic Science Award 2012).

\section{Authors' details}

Uppsala University, Hedenstierna Laboratory, Surgical Sciences Department,

Uppsala, Sweden. ${ }^{2}$ Fundación Jiménez Diaz, Intensive Care Medicine, Madrid, 
Spain. ${ }^{3}$ Insitituto de Investigación Sanitaria, IIS-FJD, Madrid, Spain. ${ }^{4}$ Hospital del SAS de Jerez, Intensive Care Medicine, Jerez de la Frontera, Spain.

${ }^{5}$ Hospital Pirvado de Comunidad, Anesthesiology, Mar del Plata, Argentina.

${ }^{6}$ Uppsala University Hospital, Anesthesiology and Critical Care Medicine,

Uppsala, Sweden.

Published: 26 September 2014

\section{Reference}

1. Laxminarayan S: The calculation of forward and backward waves in the arterial system. Med Biol Eng Comput 1979, 17(1):130.

doi:10.1186/2197-425X-2-S1-P70

Cite this article as: Santos et al:: 0985. Open lung ventilation improves conditions for right ventricle performance by decreasing pulmonary

vascular wave reflections in an experimental model of ARDS. Intensive Care Medicine Experimental 2014 2(Suppl 1):P70.

\section{Submit your manuscript to a SpringerOpen ${ }^{\mathcal{O}}$ journal and benefit from:}

- Convenient online submission

- Rigorous peer review

- Immediate publication on acceptance

- Open access: articles freely available online

- High visibility within the field

- Retaining the copyright to your article

Submit your next manuscript at $\gg$ springeropen.com 